\title{
PP/organoclay nanocomposites for fused filament fabrication (FFF) 3D printing
}

\author{
C. Aumnate ${ }^{*}$, S. Limpanart, N. Soatthiyanon, S. Khunton \\ Metallurgy and Materials Science Research Institute, Chulalongkorn University, Soi Chula 12, Phayathai Rd., \\ Pathumwan, 10330 Bangkok, Thailand
}

Received 25 February 2019; accepted in revised form 23 May 2019

\begin{abstract}
D printing has attracted a lot of attention over the past three decades. In particular the Fuse Filament Fabrication (FFF) technique, general materials require low shrinkage during cooling and viscous behavior during extrusion through a nozzle. Semi-crystalline thermoplastics and their composites are of the relevance of new materials for 3D printing. However, the crystalline structures, for instance, may have a favorable impact on their printability. In this study, polypropylene/organoclay nanocomposites were prepared by melt extrusion using a twin-screw extruder. The effects of organoclay on the thermal, rheological and morphological properties were studied to evaluate the possibility of using the polypropylene/organoclay nanocomposites as the FFF 3D printing feedstock. Dioctadecyl dimethyl ammonium chloride (D18) was successfully used to modify the clay surfaces, providing a good dispersity and wettability of organoclay in the PP matrix.
\end{abstract}

Keywords: polymer composites, polypropylene; organoclay, 3D printing, fused filament fabrication (FFF)

\section{Introduction}

3D printing technologies have been introduced to serve the highly particular needs of model creating and rapid prototyping [1]. However, it has not gained enough vitality to be commercialized until recently. 3D printing becomes more affordable through a fused filament fabrication (FFF) process since it offers advantages, including low cost, high speed, and simplicity as compared to other $3 \mathrm{D}$ printing techniques. Another advantage is the potential of printing diverse materials simultaneously. Multiple extrusion nozzles with the loading of different materials can be set up in FFF printers, so printed parts can be multifunctional with designed composition [2,3]. Conversely, one common drawback of FFF printing is that the composite materials have to be in a filament form to enable the extrusion process. It is difficult to disperse reinforcements homogeneously and remove the voids formed during the manufacturing of composite filaments. Thus, the usable material is limited to amorphous thermoplastic polymers with suitable melt viscosity to allow the good dispersion of the reinforcements. Also, the melt viscosity should be appropriate to provide structural support and low enough to enable extrusion. The general materials require low shrinkage during cooling and viscous behavior during extrusion through a nozzle. Therefore, this brings about the most exclusive use of amorphous thermoplastics in FFF. Thermoplastic polymer materials such as acrylonitrile butadiene styrene (ABS), polylactic acid (PLA), polyamide (PA) and polycarbonate (PC) could be processed by $3 \mathrm{D}$ printing technology. However, most of the 3D printed polymer products are still now used as conceptual prototypes rather than functional components, due to the intrinsically limited mechanical properties and functionalities of printed pure polymer parts. Accordingly, there is a critical need to develop printable polymer composites, including

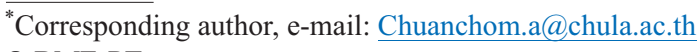

(C) BME-PT 
high precision, cost-effective and customized geometry. Semi-crystalline thermoplastic is one of the new relevance materials for $3 \mathrm{D}$ printing. However, the crystalline structure, for example, may effect mechanical properties, chemical resistance positively and may have a favorable effect on the end-use properties for various applications $[4,5]$.

Nanocomposites are multiphase solid materials where one of the phases has a dimension of $<100 \mathrm{~nm}$. The nanofillers can be in various forms such as particles, sheets (exfoliated clay stacks) or fibers. Nanoclay is one of the most commonly used nanofiller in particular for the fuel tank and fuel line components for cars [6]. Polypropylene-based composites are generally used in automotive applications to manufacture the part that may need to involve the compressive impact loading under a wide range of temperatures such as bumpers [7].

Polypropylene (PP)/clay nanocomposites find applications where excellent mechanical properties, low permeability to gases or flame resistance are essential service specifications at low clay content $[3,5]$. The development of PP/clay nanocomposites poses particular challenges because of the hydrophobicity of PP. Thus, the hydrophilic clays tend to form agglomerates during mixing with PP. This is due to the van der Waals attraction between clay particles. It is well-known that the dispersion of nanoclay in the polymer matrix depends on the surface peeling, followed by polymer chains diffusion into the nanoclay galleries [8]. The methods commonly employed to facilitate intercalation/exfoliation of the clay and maximize its interfacial contact with the polymer matrix include adding compatibilizers such as maleic anhydride grafted polymer; dimethyl maleate grafted polymer, as well as the surface modifications/treatments $[6,8-13]$. This can significantly affect the matrix morphology and usually leads to proper clay intercalation instead of exfoliation [10,11, 14]. Moreover, the cationic modification is commonly performed in an aqueous medium in which clay swell easily to produce organophilic clays. Among the methods, quaternary ammonium salts are frequently used. In such a case, the microstructural characterization concerning matrix morphology and clay dispersion, which affects the end properties of the composites, becomes crucial to understand. Melt compounding using twin-screw extruders allows the required high stress to break up the tactoid structure of the clays and to promote intercalation/exfoliation
[15]. In addition, twin-screw extruders are widely used in industry, and the process is straightforward. Accordingly, thermal and rheological properties of the composites have attracted much interest $[4,15]$. The properties of composites are dependent on different factors such as the size, shape and nature of the filler particles, interactions between their constituents, orientation, dispersion and distribution of the particles in the matrix and notably the filling level [16]. This study focuses on the development of polymer nanocomposite filaments for the FFF 3D printing process, using PP and organoclay. The typical melt extrusion process used in polymer processing technologies is performed to prepare the $\mathrm{PP} /$ organoclay nanocomposites. The thermal, rheological, morphological and tensile properties of the nanocomposites are investigated to evaluate a possibility of using PP/organoclay composites as FFF 3D printing feedstock. Such PP/organocomposites may have applications in structural, electrical/electronic and automotive fields.

\section{Experimental}

\subsection{Materials}

Sodium-bentonite clay was supplied by Thai Nippon Chemical Co. Ltd., Thailand. The surfactant used in this study was a mixture of dioctadecyl dimethyl ammonium chloride salts with alkyl chain length of 14 $(4 \%), 16(32 \%)$, and $18(58 \%)$, which will be referred to as D18 throughout the study. The surfactant was purchased from Thai Specialty Chemical Co., Ltd., Thailand. Polypropylene (PP) powder (MFI = $19.8 \mathrm{~g} / 10 \mathrm{~min}$ ) was obtained from HMC Polymer co., Ltd., Thailand.

\subsection{Organoclay preparation}

$400 \mathrm{~g}$ of Na-bentonite were added to $20 \mathrm{ml}$ of deionized water and stirred vigorously for $3 \mathrm{~h}$. Various amounts of D18 were then added in portions (Table 1) as coupling agent. The reaction mixture was heated at $70^{\circ} \mathrm{C}$ for $1 \mathrm{~h}$. The mixture suspension was finally filtered, washed and dried at $80^{\circ} \mathrm{C}$ for at least $12 \mathrm{~h}$ and then ground to fine powder.

Table 1. Organoclay modified with different D18 concentrations.

\begin{tabular}{|c|c|}
\hline Organoclay & $\begin{array}{c}\text { Dioctadecyl dimethyl ammonium chloride (D18) } \\
\text { [mmol/g Clay] }\end{array}$ \\
\hline BAD05 & 0.50 \\
\hline BAD10 & 0.10 \\
\hline BAD15 & 0.15 \\
\hline
\end{tabular}




\subsection{PP/organoclay composites preparation}

Polypropylene (PP) pellets were ground into powder form. PP powder with $30 \mathrm{wt} \%$ of organoclay (Table 1) was extruded first as a master batch using a co-rotating twin-screw extruder. The extrusion temperature profiles ramped from 180 up to $220^{\circ} \mathrm{C}$ (from the hopper to the die). The amount of the organoclay used in all the nanocomposites was kept constant as $3 \mathrm{wt} \%$ concerning total PP, according to the good mechanical performance improvement resulting from our previous study [17]. Thus, the PP/organoclay master batch was then diluted to obtain $3 \mathrm{wt} \%$ of organoclay using the same melt extrusion parameters.

\subsection{Characterization}

\subsubsection{X-ray diffraction (XRD)}

The X-ray diffraction (XRD) of organoclay was performed using an X-ray diffractometer (Bruker AXS Model D8 Discover). All samples were scanned over the range $2 \theta=2-10^{\circ}$ and the measurements were recorded at every $0.02^{\circ}$ interval.

\subsubsection{Differential scanning calorimetry}

The measurements were carried out using a DSC 3500 Sirius, under nitrogen atmosphere. The samples were heated from room temperature to $280^{\circ} \mathrm{C}$. After an isothermal step for $2 \mathrm{~min}$, the samples were cooled down to $30^{\circ} \mathrm{C}$ and finally heated up to $280^{\circ} \mathrm{C}$ after another isothermal step for $2 \mathrm{~min}$. Scanning temperature ramps of $10 \mathrm{~K} / \mathrm{min}$ were used for all dynamic steps. A heat of fusion for a $100 \%$ crystalline PP of $205 \mathrm{~J} / \mathrm{g}$ [4] was used to calculate the degree of crystallization. For isothermal analysis, all materials were quenched from $230^{\circ} \mathrm{C}$ to an isothermal temperature $\left(125^{\circ} \mathrm{C}\right)$.

\subsubsection{Rheology test}

First, dynamic strain sweep tests were performed using a rheometer (Germini 2000, TA instrument) equipped with $25 \mathrm{~mm}$ diameter parallel plates. The dynamic strain sweep test was conducted from the strain values of $0.1-100 \%$ with the frequency of $0.628 \mathrm{rad} / \mathrm{s}$ to investigate the linear regime for all samples. After that, the linear viscoelasticity responses of the materials were measured with the frequency sweep tests between 0.628 and $628 \mathrm{rad} / \mathrm{s}$ at a temperature of $210^{\circ} \mathrm{C}$. A constant strain of $2 \%$ (which is in the linear regime for all samples) was used, and the gap between the two plates was set to $1 \mathrm{~mm}$. After applying the Cox-Merz rule, the complex viscosity could be determined as a function of the shear rate.

\subsubsection{Scanning electron microscopy (SEM)}

For the examination of the organoclay dispersion in the PP matrix, the PP/organoclay nanocomposite filaments were mounted in resin. They were then metallographically ground using emery paper and polished on diamond pads. The samples were examined using a JEOL JSM-IT500HR scanning electron microscope (SEM) at an accelerating voltage of $10 \mathrm{kV}$. For imaging, backscattered electrons were used to enhance the contrast of the specimen images, compared with secondary electrons.

Furthermore, the cryo-fracture surfaces of the PP/ organoclay nanocomposite filament were also studied using a Hitachi SU3500 scanning electron microscope at an accelerating voltage of $15 \mathrm{kV}$. Prior to investigation, all samples were sputter coated with gold.

\subsubsection{Transmission electron microscopy (TEM)}

All PP/organoclay nanocomposite samples were investigated using the transmission electron microscope (TEM), (JEOL 2010 with an acceleration voltage of $200 \mathrm{kV}$ ) to verify the dispersion of organoclay in the PP matrix. The PP/organoclay nanocomposite filaments were prepared as a $90 \mathrm{~nm}$ thick slice using a microtome with a diamond knife in liquid nitrogen. The slices were then imaged in the TEM.

\subsubsection{Tensile tests}

To obtain the mechanical properties, the tensile tests were carried out according to ASTM D638 [18]. The specimens were printed based on Type- $\mathrm{V}$ geometry. The crosshead speed was set to $5 \mathrm{~mm} / \mathrm{min}$. Ultimate tensile strength; Young's modulus and elongation at break were evaluated as an average value of at least five replicates.

\section{Results and discussion}

\subsection{X-ray diffraction}

The XRD analysis allows estimating the distance between the clay layers according to Bragg's law [15] as shown in Equation (1):

$2 d \sin \theta=n \lambda$

where $d$ represents the spacing between diffraction lattice planes, $\theta$ is the diffraction angle of the beam 
on these planes, $n$ is a positive integer representing the diffraction order, and $\lambda$ corresponds to the wavelength of the X-ray radiation used in the diffraction experiment. Based on the interaction force of the polymer/organoclay, three types of nanocomposite morphologies could be generated, including intercalation, exfoliation and phase-separation.

The intercalated morphology resulted in a displacement of the peaks associated with the basal distance toward angles' lower values, corresponding to a distance between the most critical sheets. Exfoliated morphology resulted in the absence of diffraction peak because of a much too large spacing between the layers, or the nanocomposite does not present ordering anymore $[19,20]$.

Figure 1 presents the XRD patterns of the unmodified clay, organoclay modified with different D18 contents as well as PP and PP/organoclay nanocomposites, respectively, from the region of $2 \theta$ between 2 to $10^{\circ}$. For the clay modified with the series of different D18 loading, the peak intensity was increased with increasing the D18 content. Besides, the peaks tended to shift toward the lower angle values (see Figure 1a). These results indicated that there exists a difference in the clay microstructure after organically modified the clay surface with D18. The similar results were also found in the case of the PP/organoclay nanocomposites as depicted in Figure 1b. There was no peak observed for the neat PP observed in the interesting region. For the PP/organoclay composites,

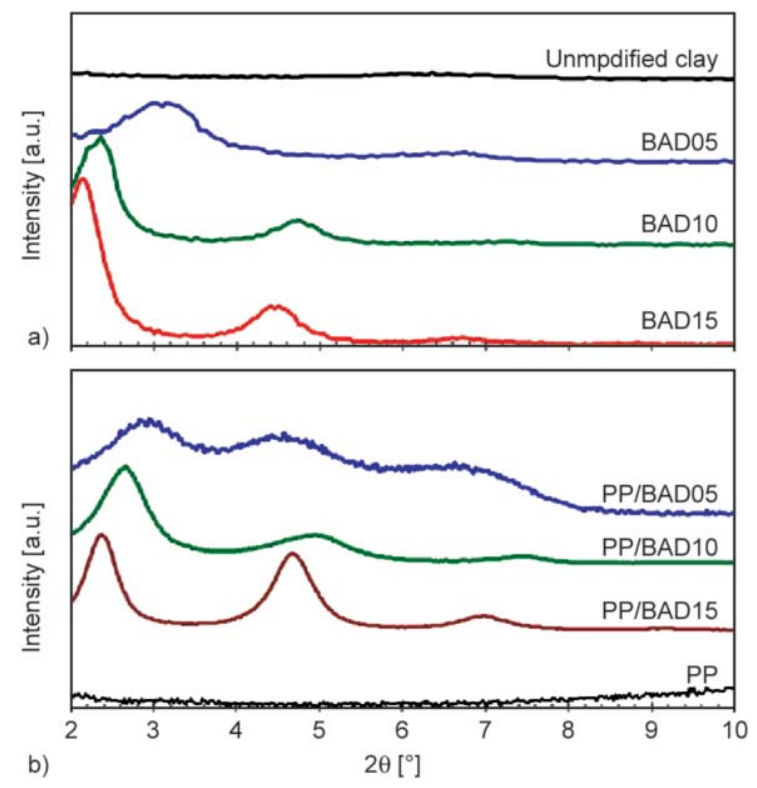

Figure 1. XRD patterns of (a) unmodified clay and organoclay modified with different D18 contents and (b) neat PP and PP/organoclay nanocomposites. the examined diffraction peaks shifted toward lower angle values as the D18 contents increased. The peak of PP/BAD05 observed at the $2 \theta$ value of $3.0^{\circ}$, corresponded to $37.2 \AA d$-spacing. With increasing the D18 contents, the broader distribution of the $d$-spacing value was also observed. The $d$-spacing values were $33.3 \AA\left(2 \theta=2.7^{\circ}\right)$ and $29.8 \AA\left(2 \theta=2.4^{\circ}\right)$ for for PP/BAD10 and PP/ BAD15, respectively. PP is nonpolar and does not interact perfectly with clay platelets. However, due to the high shear during the melt extrusion process as well as the addition of the coupling agent, the combination of intercalation and exfoliation could be achieved in the composites despite the non-polarity of PP. The lower angle values revealed intercalation while the larger $d$-spacing values suggested exfoliation developed in the PP/organoclay nanocomposites, which allowed peeling of the clay platlets.

From our previous study, the D18 molecules can be either packed as an island of interdigitating monolayers or an island of highly tilted bilayers on the clay surface, leading to the increase in $d$-spacing value [17]. For the small loading of D18 (PP/BAD05), even though the stacking of the organoclay has not completely disappeared, the peaks have slightly broadened. It is possible that the clay surface has not yet fully covered with the D18 molecules, leaving the empty space around the island where the hydrate water- $\mathrm{Na}^{+}$is located, resulting in a less ordered structure.

\subsection{Thermal properties}

In FFF 3D printing, temperatures of the nozzle are crucial parameters to print the composite filaments without major structural flaws smoothly. Thus, thermal properties of such composite filament were carefully assessed with standard techniques, differential scanning calorimetry (DSC). The printable materials need to be heated above the glass transition temperature $\left(T_{\mathrm{g}}\right)$ or the melting temperature $\left(T_{\mathrm{m}}\right)$ to get softened the composites. However, if the temperature is set too high, it could degrade the polymer ingredients. Therefore, before $3 \mathrm{D}$ printing, $T_{\mathrm{g}}$ or $T_{\mathrm{m}}$ of the materials is the first and most vital parameter to be determined.

Figure 2 shows the representative DSC curves of the $\mathrm{PP}$ and the PP/organoclay nanocomposites. In general, the variation in the melting temperature $\left(T_{\mathrm{m}}\right)$ indicates the change of crystal structures of material. The $T_{\mathrm{m}}$ of nanocomposites could be changed upon 


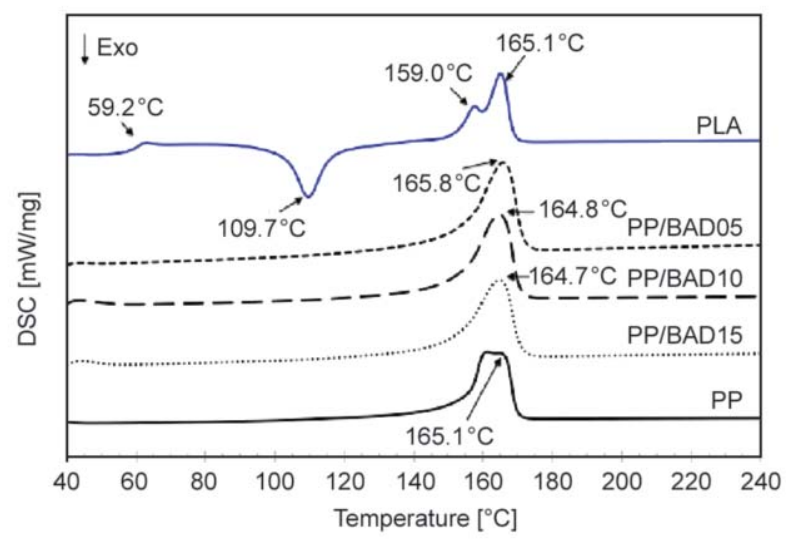

Figure 2. Melting temperatures of PP and PP/organoclay nanocomposites in comparison with PLA, the conventional material used for FFF 3D printing.

filler loading. However, there is no significant difference between Tm for the PP and the PP/organoclay nanocomposites. Since the amount of organoclay loading in all of the PP/organoclay nanocomposites in this study were kept constant at $3 \mathrm{wt} \%$, this justified that the concentration of D18 does not considerably affect the thermal stability of the PP.

A relatively broad melting peak at $165^{\circ} \mathrm{C}$ is characteristic of the $\alpha$-phase of iPP [21]. In comparison with the conventional PLA filament, the PP and the PP/ organoclay nanocomposites could be softened at the nearly same temperature $\left(T_{\mathrm{m}} \sim 165^{\circ} \mathrm{C}\right)$. It could be implied that the PP and the PP nanocomposites could be possibly $3 \mathrm{D}$ printed using the same temperature setup for the conventional PLA filament. Hence, the developed PP and PP/organoclay nanocomposite filaments can be 3D printed using the conventional FDM 3D printers.

Figure 3 shows the crystallization temperature $\left(T_{\mathrm{c}}\right)$ for the PP and the PP/organoclay nanocomposites. The

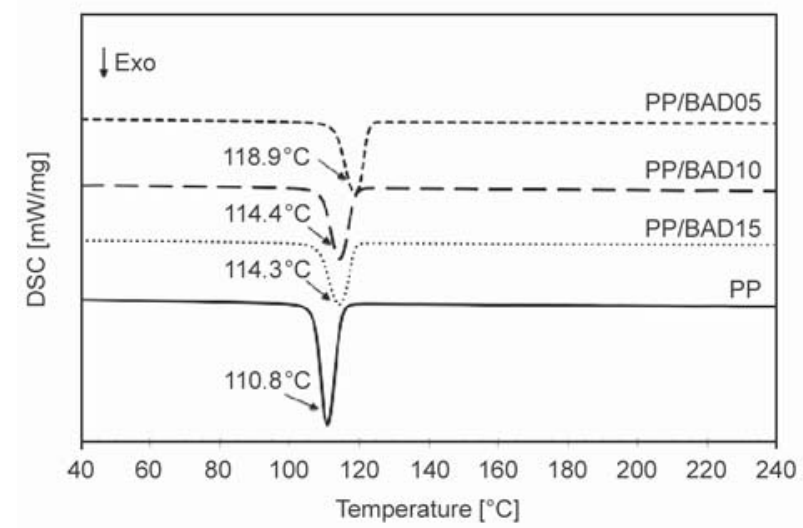

Figure 3. Crystallization temperature of $\mathrm{PP}$ and its composites; PP/BAD05, PP/BAD10 and PP/BAD15.
Table 2. Differential scanning calorimetry results of neat PP and $\mathrm{PP} /$ organoclay nanocomposites.

\begin{tabular}{|l|c|c|c|c|c|c|c|}
\hline Samples & $\begin{array}{c}\boldsymbol{T}_{\mathbf{m}} \\
{\left[{ }^{\circ} \mathbf{C}\right]}\end{array}$ & $\begin{array}{c}\boldsymbol{T}_{\mathbf{c}} \\
{\left[{ }^{\circ} \mathbf{C}\right]}\end{array}$ & $\begin{array}{c}\boldsymbol{X}_{\mathbf{c}}{ }^{*} \\
{[\mathbf{\%}]}\end{array}$ & $\begin{array}{c}\boldsymbol{T}_{\mathbf{m} \text { (start) }} \\
{\left[{ }^{\circ} \mathbf{C}\right]}\end{array}$ & $\begin{array}{c}\boldsymbol{T}_{\mathbf{c} \text { (start) }} \\
{\left[{ }^{\circ} \mathbf{C}\right]}\end{array}$ & $\begin{array}{c}\Delta \boldsymbol{H}_{\mathbf{c}} \\
{[\mathbf{J} / \mathbf{g}]}\end{array}$ & $\begin{array}{c}\Delta \boldsymbol{H}_{\mathbf{m}} \\
{[\mathbf{J} / \mathbf{g}]}\end{array}$ \\
\hline PP & 165.1 & 110.8 & 46.8 & 155.4 & 114.9 & 99.4 & 96.0 \\
\hline PP/BAD05 & 165.8 & 118.9 & 35.6 & 154.4 & 122.8 & 73.0 & 73.0 \\
\hline PP/BAD10 & 164.8 & 114.4 & 33.4 & 153.6 & 118.8 & 69.6 & 68.4 \\
\hline PP/BAD15 & 164.7 & 113.9 & 30.0 & 152.5 & 118.9 & 58.6 & 61.6 \\
\hline
\end{tabular}

${ }^{*}$ Heat of fusion, $\Delta H_{\mathrm{m}}$ for $100 \%$ crystalline $\mathrm{PP}=205.0 \mathrm{~J} / \mathrm{g}$ [18].

crystallization temperatures of all the $\mathrm{PP} /$ organoclay nanocomposites were found to be higher than that of pure PP. The PP/BAD10 and PP/BAD15 presented a nearly similar crystallization behavior whereas the PP/BAD05 showed the highest crystallization temperature. The shifts of both the onset and peak toward higher temperatures for all the PP/organoclay nanocomposites were observed as compared to pure PP. This clearly illustrates that the crystallization of PP significantly affected by both the presence of D18 and the clay. These effects on the crystallization were in agreement with the importance of the spherulite size reduction. Organoclay acted as nucleating sites and induced crystallization of the PP matrix. The degree of crystallization for materials with short molecules was high since they could crystallize faster and more accessible [22]. As shown in Table 2, the degree of crystallinity decreased with increasing the D18 content. The addition of D18 delayed the crystallization process as shown in Figure 4.

When the higher content of D18 was added into the nanocomposites, the crystallization behavior tended to be much more similar to the PP, in agreement again with the weaker reductions in spherulite size compared to the pure PP. However, for the small

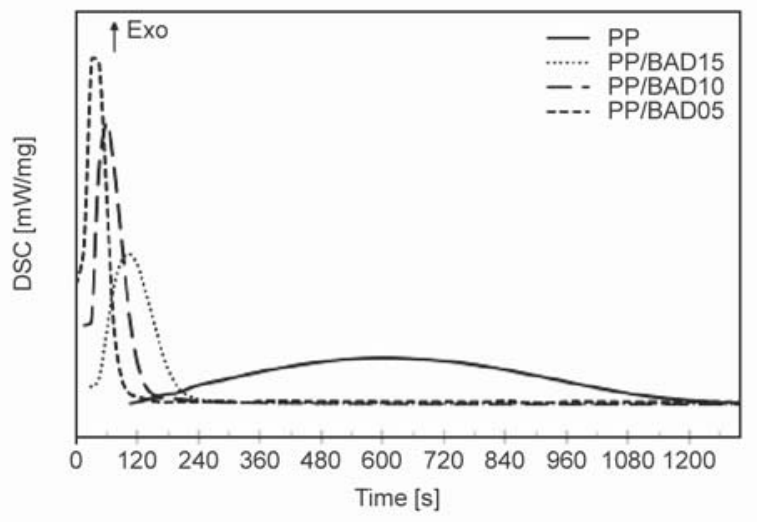

Figure 4. Isothermal segments of the crystallization process at $125^{\circ} \mathrm{C}$ of $\mathrm{PP}$ its composites; PP/BAD05, PP/ $\mathrm{BAD} 10$ and PP/BAD15. 
amount of D18 (PP/BAD05), the significant shift of $T_{\mathrm{m}}$ to the higher temperature was observed, indicating the substantial reduction in spherulite size as well as the faster crystallization of the composite. These results thus suggested that the amount of D18 played an essential role in the crystallization behavior and also the degree of crystallinity. Furthermore, the enthalpy tended to drop with an increase in D18 content. This phenomenon may be also attributed to a decrease of the thermodynamically stable alpha phase content in favor of a mesomorphic structure [23].

\subsection{Rheological behaviors}

The viscosity of the polymer melt usually plays an important role in the processability of materials. Understanding rheological properties is of great importance to achieve an overview of the material's structures and also the determination of processing conditions for real polymer processing, such as extrusion and injection molding. The crucial challenge is to find the optimum balance between improvements in properties, at the same time being able to process the materials. Polymer composites are mainly processed under high temperatures and high shear rates. There are several drawbacks resulted from mixing hard particles with polymers, principally due to the considerable difference in densities. Adding solid particles into a molten polymer changes the viscoelastic behavior, the viscosity and the elasticity of the system.

The dynamic strain sweep test was first applied to the neat $\mathrm{PP}$ and $\mathrm{PP} /$ organoclay nanocomposites to determine the linear viscoelastic region. Figure 5 presents the storage modulus $\left(G^{\prime}\right)$, which is a sensitive rheological function related to the structural changes of the nanocomposites [12]. Storage modulus $\left(G^{\prime}\right)$ of

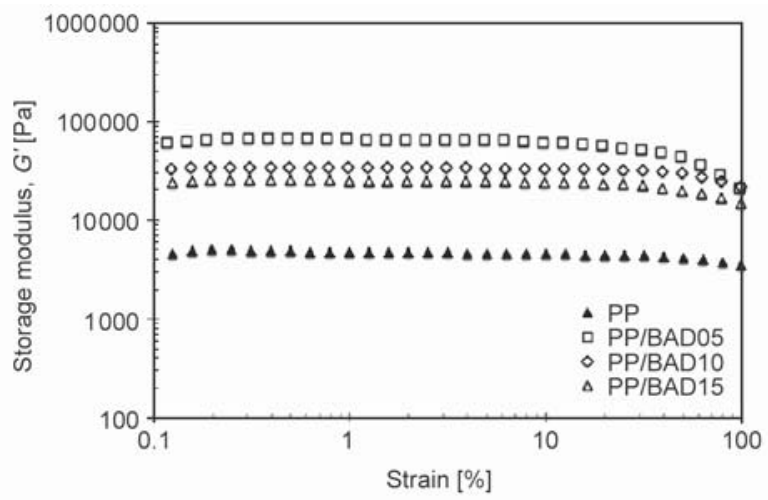

Figure 5. Storage modulus $\left(G^{\prime}\right)$ versus strain $(\gamma)$ curves for neat $\mathrm{PP}$ and its organoclay nanocomposites at the temperature of $230^{\circ} \mathrm{C}$. all samples exhibits a linear region (Newtonian plateau) at low strain and the non-linear region at high strain amplitudes. The addition of organoclay increased the plateau modulus. The transition point, which appeared at the deviation region from the linear to non-linear viscoelastic behavior, is defined as a critical strain $\left(\gamma_{c}\right)$. It was observed that the critical strain $\left(\gamma_{\mathrm{c}}\right)$ for the PP/organoclay nanocomposites varies with the D18 content. However, at the strain less than $10 \%$, all samples exhibit linear viscoelastic behavior. Therefore, all further rheological measurements in this study were done in the linear regime at $2 \%$ strain.

Frequency sweep tests for the PP/organoclay nanocomposites in the linear viscoelastic domain are shown in Figure 6. The storage modulus $\left(G^{\prime}\right)$ was increased by the incorporation of the organoclay into the PP matrix. The enhancement in the dynamic modulus was significant, in particular, at low frequencies regime. Also, $G^{\prime}$ becomes nearly independent on the frequency at low frequencies, which is an evidence of the exfoliation or partial exfoliation [11]. It can be explained that the diffusion of the organoclay molecules is favored by making the galleries chemically compatible with the PP matrix. The compatibility occurs by exchanging interlayers inorganic clay cations with D18 cations. Therefore, layer distance (gallery distance) of organoclay increases due to the modifier. With the same loading of organoclay, $G^{\prime}$ value is molder with higher D18 content. This reflects the less effective development of the physical interaction between the PP chains and the layer of organoclay at higher D18 content.

Figure 7 shows the variation of the complex viscosity for the neat PP, PP/BAD05, PP/BAD10, and PP/ BAD15 nanocomposites. It was well established that

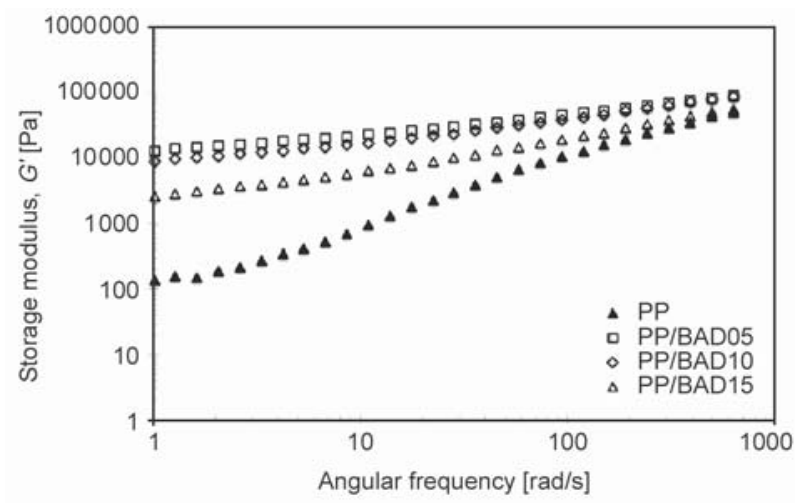

Figure 6. Frequency variations of the storage modulus, $G^{\prime}$ curves for neat PP and its organoclay nanocomposites at the temperature of $230^{\circ} \mathrm{C}$. 


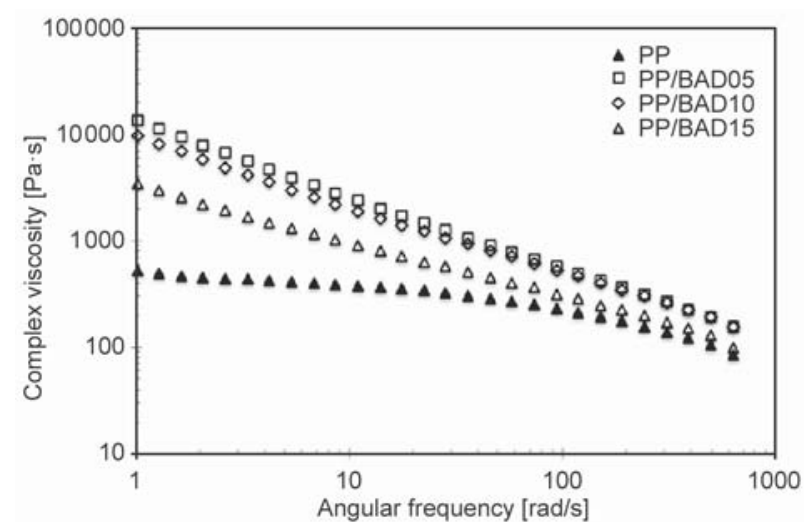

Figure 7. Complex viscosity curves for neat PP and its organoclay nanocomposites at the temperature of $230^{\circ} \mathrm{C}$.

the addition of nanofillers into the polymer matrix increased the viscosity of the system. When solid particles were added into a polymer matrix, they might disturb the flow lines and restricted the mobility of the polymer chains. The increase of the viscosity values also proves the physical network-like structure developed in the PP/organoclay nanocomposites. Furthermore, it should be noted that all the PP/organoclay nanocomposites exhibited shear-thinning behavior for the complex viscosity without any plateau region at low frequencies. Pronounced shear thinning has also been reflected the nanodispersion which is another evidence of the exfoliation morphology [11]. Also, by applying the Cox-Merz rule, Figure 8 presents the shear viscosity of the PP and its nanocomposites. The average shear rate in the typical co-rotating twin-screw ranges between 1 and $1000 \mathrm{~s}^{-1}$ [24]. For the FFF 3D printer, the relatively low shear rate is expected near the liquefier entrance and the print nozzle. Shear rates in the nozzle are commonly in the range of $100-200 \mathrm{~s}^{-1}$ [25]. Table 3 illustrates the

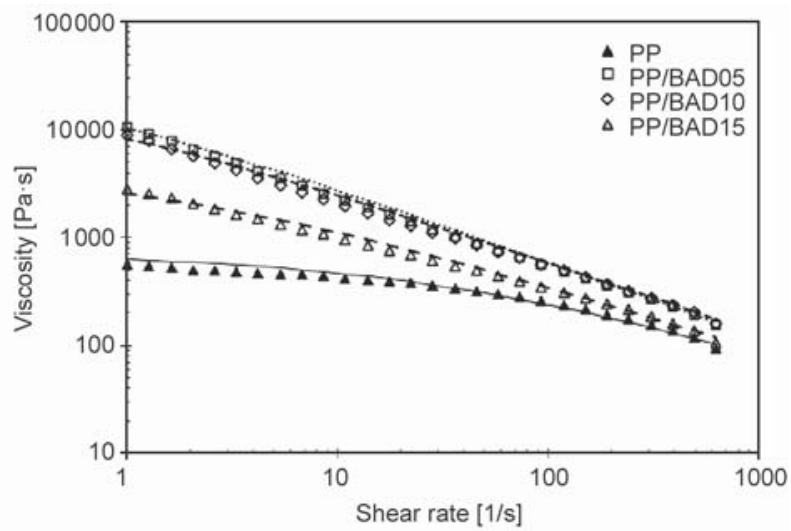

Figure 8. Shear viscosity (applied Cox-Merz rule) curves for neat PP and its organoclay nanocomposites at the temperature of $230^{\circ} \mathrm{C}$.
Table 3. Shear thinning exponent and viscosities of neat PP and $\mathrm{PP} /$ organoclay composites.

\begin{tabular}{|l|c|c|c|}
\hline \multicolumn{1}{|c|}{ Samples } & $\boldsymbol{\eta}$ at $_{\mathbf{1 0 0 ~ s}}$ & $\boldsymbol{\eta}$ at $\mathbf{2 0 0 ~ s}$ & $\boldsymbol{\eta}$ at $\mathbf{1 0 0 0 ~ s}$ \\
\hline PP & 235.56 & 176.42 & 80.73 \\
\hline PP/BAD05 & 581.77 & 360.43 & 117.64 \\
\hline PP/BAD10 & 578.87 & 369.49 & 128.98 \\
\hline PP/BAD15 & 339.90 & 230.17 & 90.50 \\
\hline
\end{tabular}

viscosities of the PP and the PP/organoclay nanocomposites at the shear rate of 100,200 and $1000 \mathrm{~s}^{-1}$. As expected, PP/BAD15, the nanocomposites with the highest degree of D18 loading displayed the lowest viscosity among the $\mathrm{PP} /$ organoclay nanocomposites at all shear rates. This can be attributed to the effect of the shorter molecule of D18, which flow easier than the longer molecules, PP. Addition of D18 led to the improvement of the flowability of the nanocomposites. However, incorporating with the $G^{\prime}$ and XRD results, the capability of the exfoliation and intercalation of the PP/organoclay nanocomposites could be improved by modifying clay with the coupling agent, D18. The less amount of D18 resulted in the higher degree of exfoliation/intercalation.

Figure 9 shows a Cole-Cole plot of the storage modulus $G^{\prime}$ versus the loss modulus $G^{\prime \prime}$ for the neat PP and its organoclay nanocomposites at $230^{\circ} \mathrm{C}$. It was proposed that the $\log G^{\prime}-\log G^{\prime \prime}$ should be similar if the microstructure does not alter [26]. The $\log G^{\prime}-\log G^{\prime \prime}$ curve can also be used to elucidate structure differences of polymer materials at a fixed conditions such as a fixed temperature. The increase of $G^{\prime}$ at a given $G^{\prime \prime}$ indicated that the microstructure of the composites changed significantly with the addition of organoclay. Also, the organoclay modified with higher



Figure 9. Storage modulus $\left(G^{\prime}\right)$ as a function of loss modulus $\left(G^{\prime \prime}\right)$ of neat PP and its organoclay nanocomposites at the temperature of $230^{\circ} \mathrm{C}$. 
D18 content resulted in the less structural deviation as compared to the neat PP.

\subsection{Morphology}

The homogeneity of organoclay dispersion directly affected the composite's printing ability and other physical properties. The dispersion of organoclay in the PP matrix was investigated via the polished surfaces of the PP/organoclay composites as shown in Figure 10. It is seen that the smaller size of the organoclay is found for the case of more substantial D18 loading content.

Figure 11 shows the SEM images for fracture surface of the PP/clay composites filaments. With low D1 8 content, the PP/BAD05, the matrix coverage was not sufficient. It can be seen from many voids appeared as some evidences of the organoclay pullout from the PP matrix. This indicated the weak interfacial bonding between the organoclay and the PP matrix. With increasing the D18 content, the matrix coverage was improved. This could be explained by

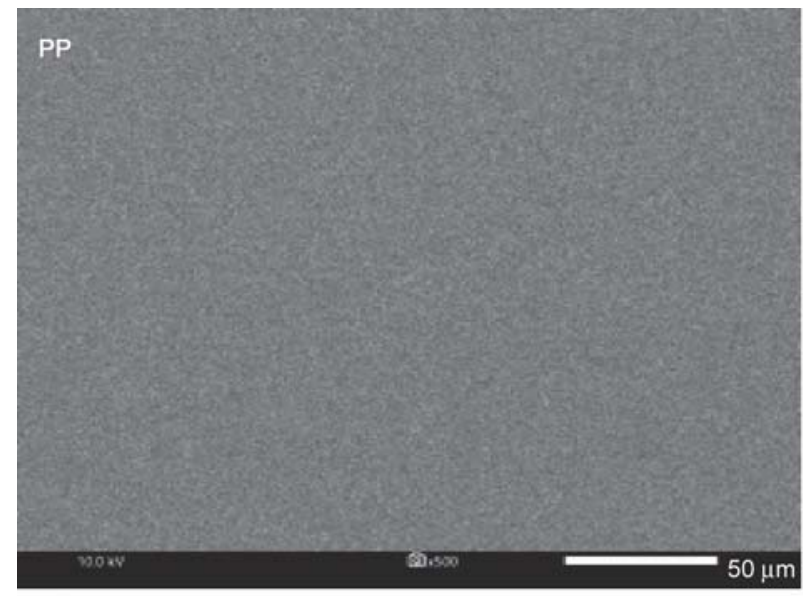

a)

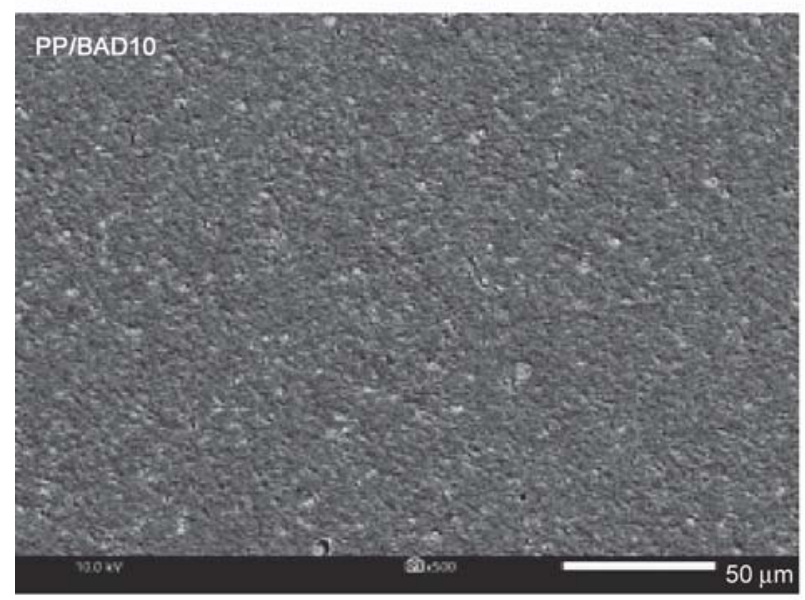

c) the fact that the high mobility of the low molecular weight coupling agent, D18, allowed the PP matrix to interact actively with a large number of clay platelets during compounding.

The morphology of the PP/organoclay nanocomposites reported in this section were in good agreement with the rheological properties, confirming the capability of dispersion as well as the consequent formation of interfacial adhesion between the modified clay and the PP matrix.

\subsection{D printing optimization \\ 3.5.1. Nozzle temperature}

For FFF 3D printing, with the extrusion temperature known, the accuracy of machine's motions can be explored [27, 28]. Figure 12 shows the extruded mass as a function of temperature for the PP/BAD05 in comparison with the conventional PLA filament. Both materials tended to display a plateau at the temperatures higher than $220^{\circ} \mathrm{C}$. The edge of the plateau region is considered the lower bound of acceptable

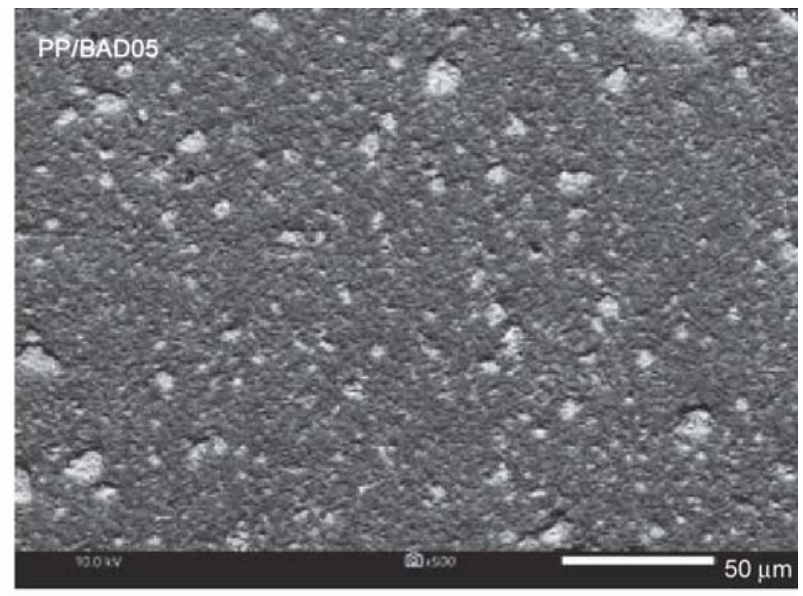

b)

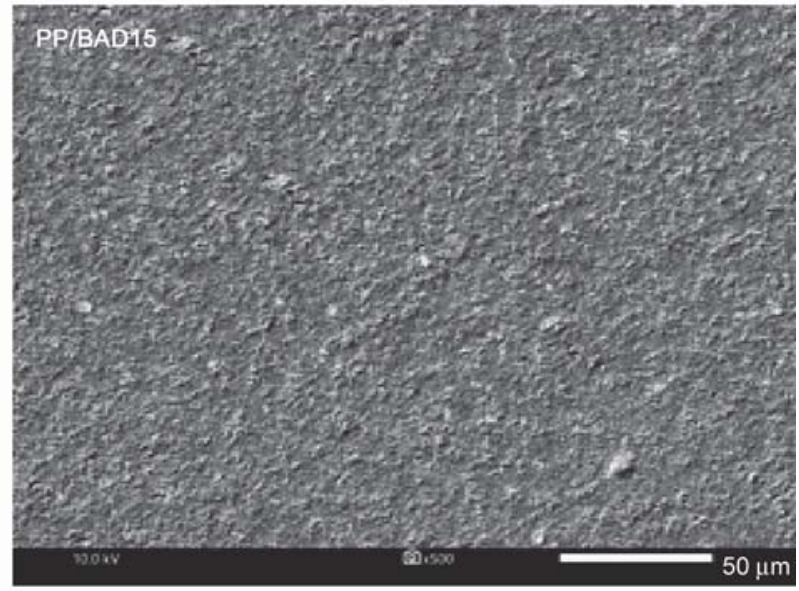

d)

Figure 10. SEM images of polished surfaces for neat $\mathrm{PP}$ and its organoclay nanocomposites at $500 \times$ magnification. a) PP, b) PP/BAD05, c) PP/BAD10, d) PP/BAD15. 


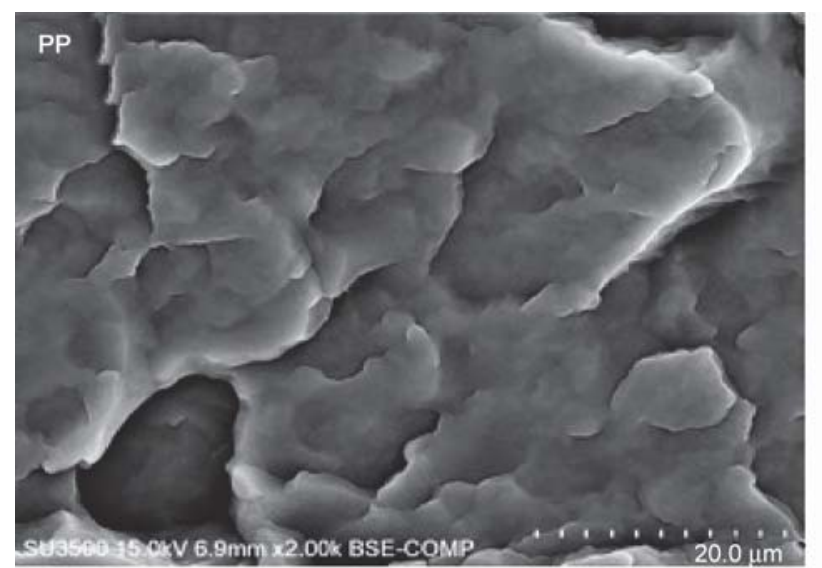

a)

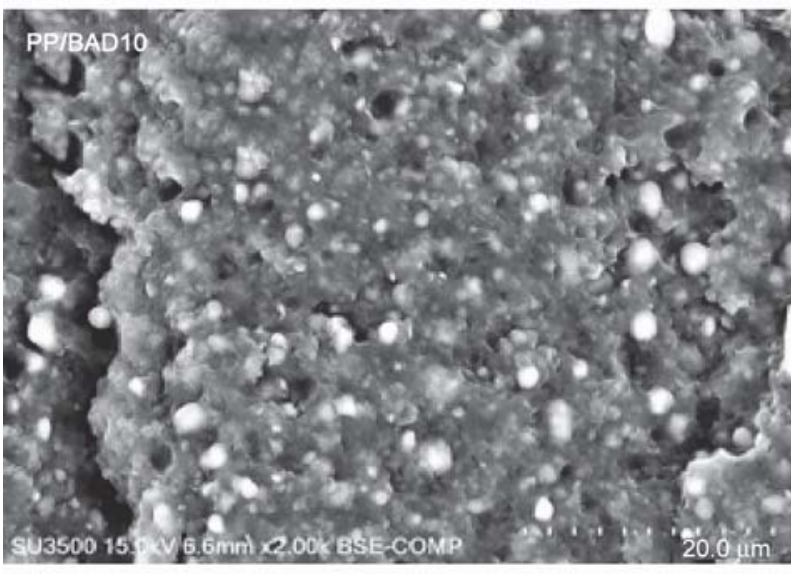

c)

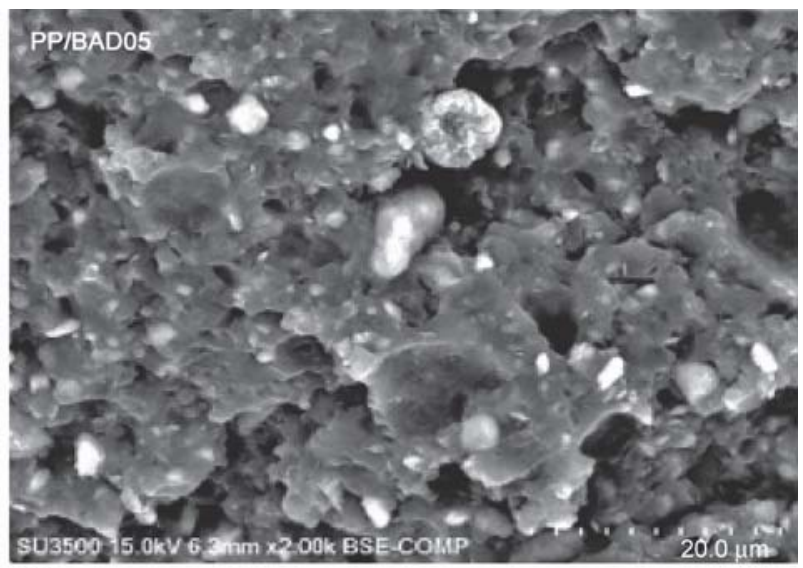

b)

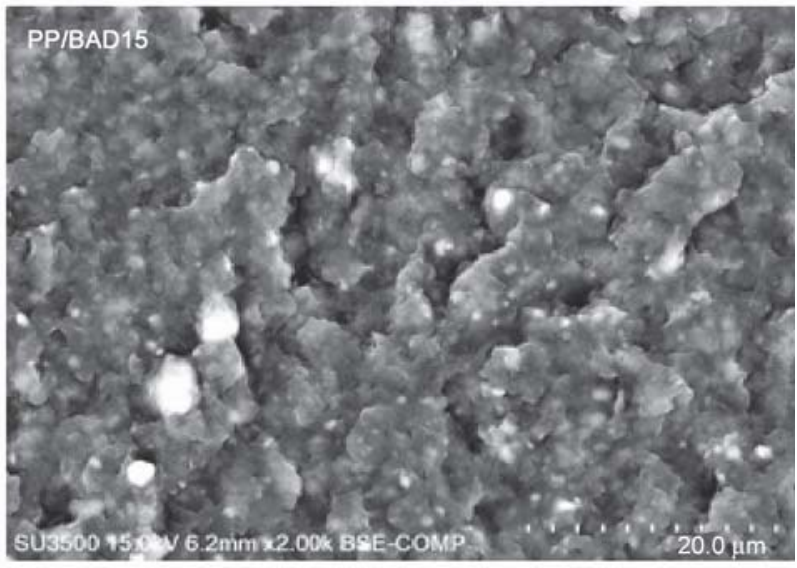

Figure 11. SEM images of fracture surfaces for neat PP and its organoclay nanocomposites at $2000 \times$ magnification. a) PP, b) PP/BAD05, c) PP/BAD10, d) PP/BAD15.

temperatures for the extrusion rate. Below this temperature, the theoretical amount of polymer extruded cannot be accurately achieved at the given feed rate. Furthermore, extruding at the higher temperature than this lower bound would cause the slower solidification of the extruded bead on the printed part. From the results, it could be concluded that PP/BAD05 could be $3 \mathrm{D}$ printed at the temperature range of $220-240^{\circ} \mathrm{C}$.



Figure 12. Extruded mass as a function of nozzle temperatures for PP/BAD05 and PLA filaments.

\subsubsection{Tensile properties}

In this study, an open source 3D printer, WANHAO Duplicator 6, was used to 3D print the tensile test specimens based on ASTM D638-14 [18]. It is noted that all prepared $\mathrm{PP} /$ organoclay nanocomposites can be $3 \mathrm{D}$ printed using the same printing parameters listed in Table 4. However, the neat PP cannot be successfully $3 \mathrm{D}$ printed because of its semi-crystalline characteristic, which leads to the high shrinkage and warpage during printing.

The tensile properties at room temperature of the PP/BAD05 and PP/BAD15 were shown in Figure 13.

Table 4. Parameters used for $3 \mathrm{D}$ printing of PP/organoclay nanocomposites.

\begin{tabular}{|ll|c|}
\hline \multicolumn{2}{|c|}{ Parameters } & Value \\
\hline Print nozzle diameter & {$[\mathrm{mm}]$} & 0.4 \\
\hline Nozzle temperature & {$\left[{ }^{\circ} \mathrm{C}\right]$} & 220 \\
\hline Bed temperature & {$\left[{ }^{\circ} \mathrm{C}\right]$} & 110 \\
\hline Layer height & {$[\mathrm{mm}]$} & 0.2 \\
\hline Print infill & {$[\%]$} & 30 \\
\hline Print speed & {$\left[\mathrm{mm} \cdot \mathrm{s}^{-1}\right]$} & 20 \\
\hline
\end{tabular}



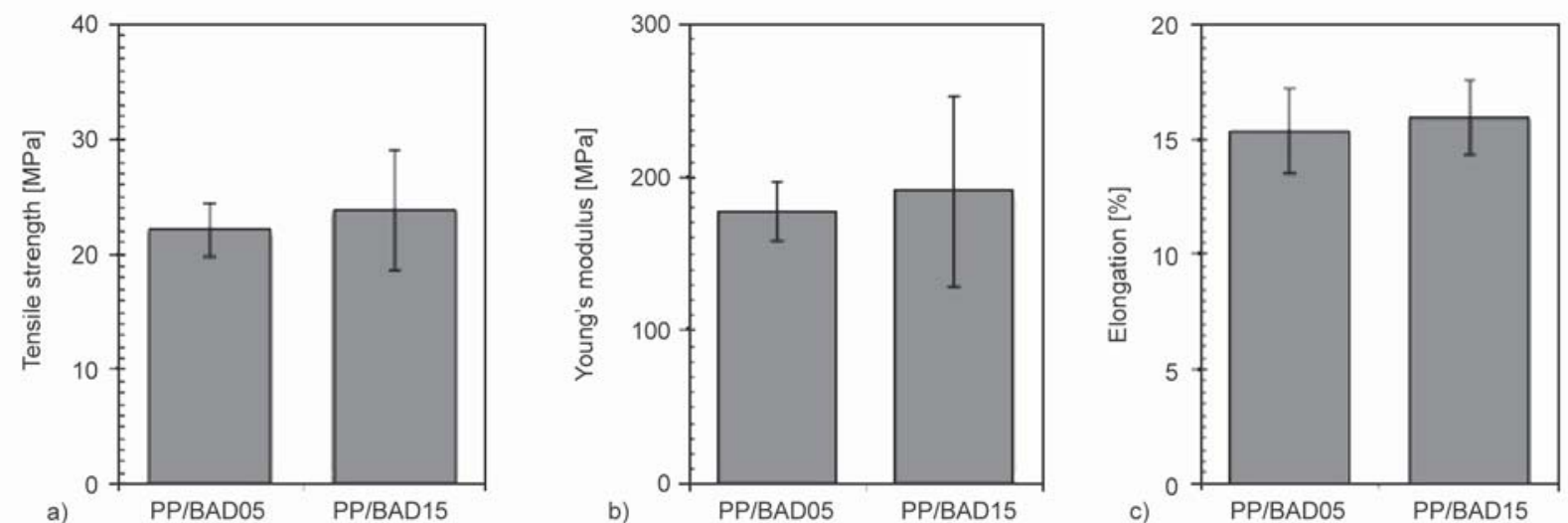

Figure 13. Tensile strength, Young's modulus and Elongation at break of PP/BAD05 and PP/BAD15 printed specimens. a) Tensile strength, b) Young's modulus, c) elongation at break.
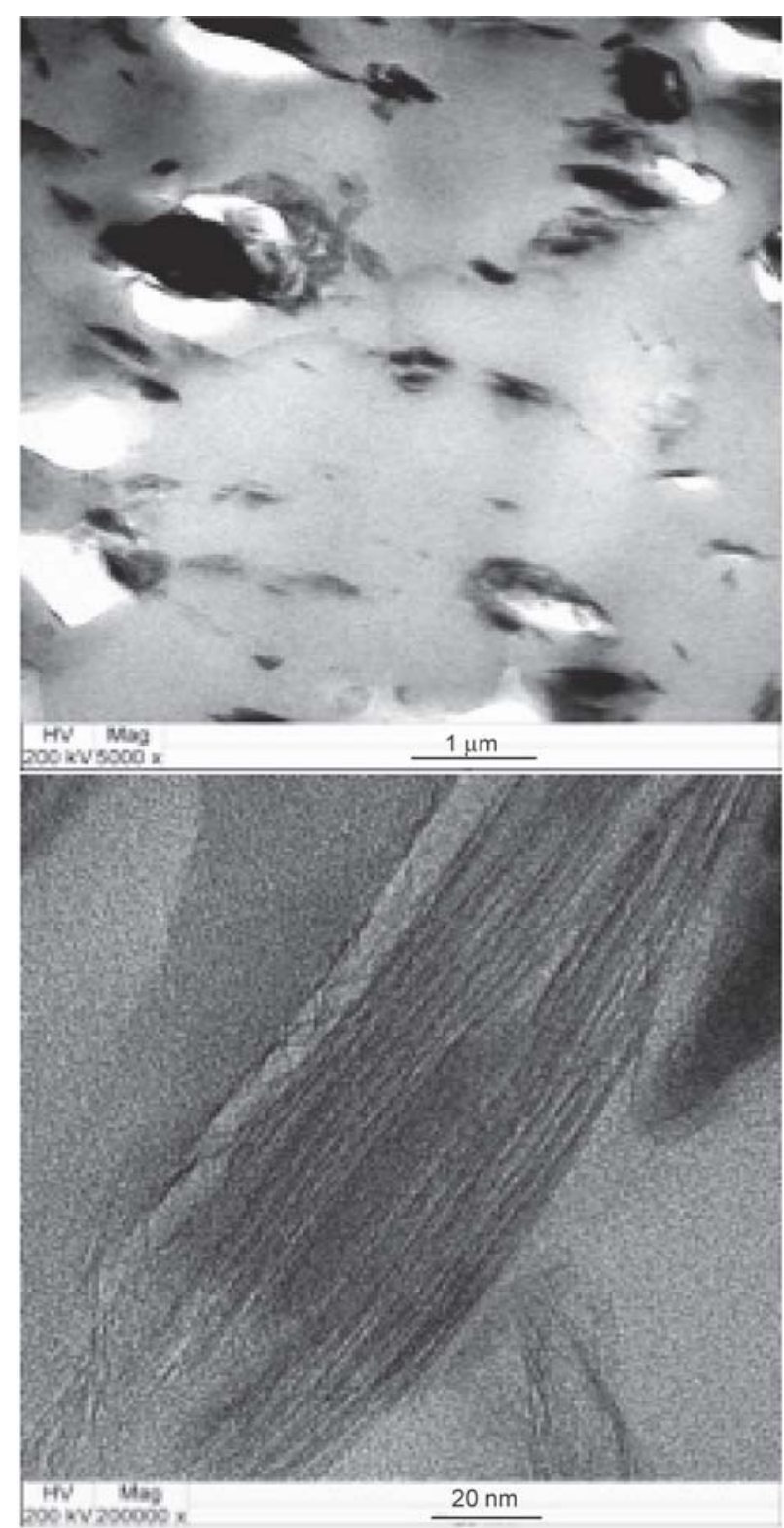

a)

PPIBAD05

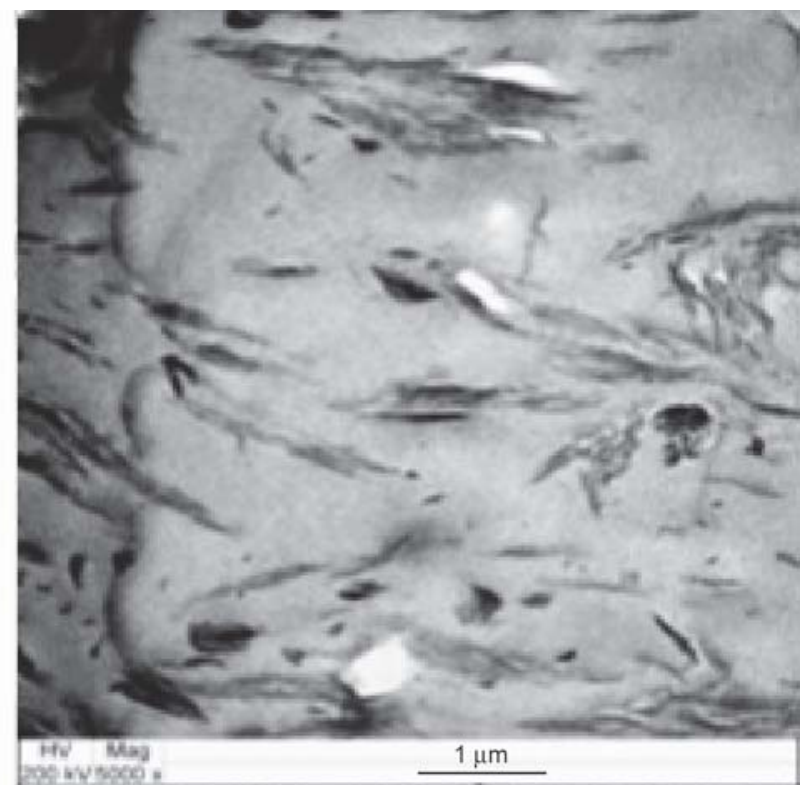

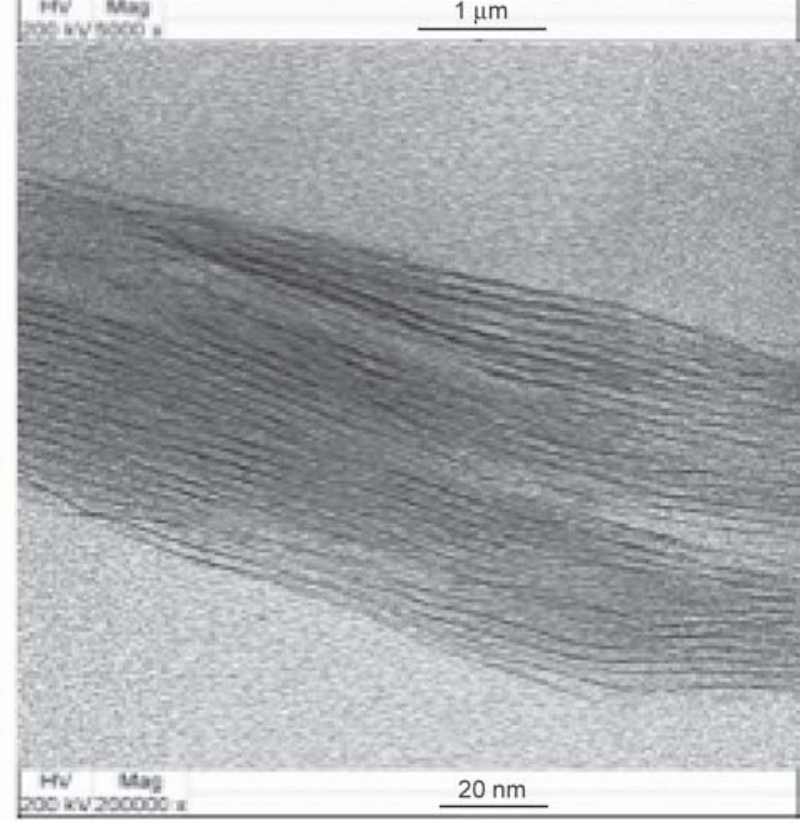

b)

PP/BAD15

Figure 14. TEM images of the 3D printed (a) PP/BAD05 and (b) PP/BAD15 at 5000× (top) and $200000 \times$ (bottom) magnifications. 
The tensile strength, Young's modulus as well as the elongation at break of the PP/BAD15 were marginally higher than those of the PP/BAD05. This could be attributed to the better dispersion of the organoclay (BAD15) in the PP matrix. These results were in good agreement with the rheological behaviors and SEM results.

\subsubsection{Organoclay dispersion}

To verify the dispersion of the organoclay and its microstructure in the PP matrix, the TEM images of the printed PP/BAD05 and PP/BAD15 were presented in Figure 14. At the same magnification $(5000 \times)$, the organoclay modified with higher D18 content (PP/ BAD15) showed a smaller size and better dispersion in the PP matrix than the PP/BAD05. Both the PP/ BAD05 and the PP/BAD15 seem to a combination of exfoliation and intercalation morphologies as anticipated by the XRD analysis. However, it is observed that the PP/BAD15 sample has larger clay tactoids which correspond to the more likely intercalated morphology [12].

\section{Conclusions}

In this study, a new PP/organoclay nanocomposite filament was first-time successfully prepared by the melt intercalation method using a twin-screw extruder and 3D printed into the three-dimensional shape. The linear viscoelasticity responses of the PP/organoclay nanocomposites showed the significant effect of the clay addition. D18 was successfully used to modify the clay surfaces, providing a better dispersion and wetting of the clay particles in the hydrophobic polymer matrix such as PP. A shift of the ( $\left.\begin{array}{lll}0 & 0 & 1\end{array}\right)$ plane peak to lower angle, indicated the more intercalation capability, while the larger $d$-spacing values suggested exfoliation developed in the PP/ organoclay composites. Combining the XRD results, the rheological behavior and the TEM results together, it can be concluded that the PP/organoclay nanocomposites prepared in this study have mixed intercalated/exfoliated microstructure. A pseudo-MFI measurement proposed that the PP/organoclay nanocomposites could be $3 \mathrm{D}$ printed at the temperature range of $220-240^{\circ} \mathrm{C}$ using a conventional FFF 3D printer. The results of this study can be further used for facilitating the development of engineering materials based on semicrystalline polymers from plastic industries.

\section{Acknowledgements}

We thankfully acknowledge the financial support from Grants for Development of New Faculty Staff, Ratchadaphiseksomphot Endowment Fund, Chulalongkorn University and The Thailand Research Fund (TRG6180009).

\section{References}

[1] Ligon S. C., Liska R., Stampfl J., Gurr M., Mülhaupt R.: Polymers for 3D printing and customized additive manufacturing. Chemical Reviews, 117, 10212-10290 (2017).

https://doi.org/10.1021/acs.chemrev.7b00074

[2] Wei X., Li D., Jiang W., Gu Z., Wang X., Zhang Z., Sun Z.: 3D printable graphene composite. Scientific Reports, 5, 11181/1-11181/7 (2015). https://doi.org/10.1038/srep11181

[3] Wang L., Gardner D. J.: Effect of fused layer modeling (FLM) processing parameters on impact strength of cellular polypropylene. Polymer, 113, 74-80 (2017). https://doi.org/10.1016/j.polymer.2017.02.055

[4] Ehrenstein G. W., Riede G., Trawiel P.: Thermal analysis of plastics. Hanser, München (2004).

[5] Sharma S. K., Nayak S. K.: Surface modified clay/polypropylene (PP) nanocomposites: Effect on physico-mechanical, thermal and morphological properties. Polymer Degradation and Stability, 94, 132-138 (2009). https://doi.org/10.1016/j.polymdegradstab.2008.09.004

[6] Kumar V., Singh A.: Polypropylene clay nanocomposites. Reviews in Chemical Engineering, 29, 439-448 (2013).

https://doi.org/10.1515/revce-2013-0014

[7] Wang K., Bahlouli N., Addiego F., Ahzi S.: Elastic and yield behaviors of recycled polypropylene-based composites: Experimental and modeling study. Composites Part B: Engineering, 99, 132-153 (2016).

https://doi.org/10.1016/j.compositesb.2016.06.033

[8] Morajane D., Shinha Ray S., Bandyopadhyay J., Ojijo V.: Impact of melt-processing strategy on structural and mechanical properties: Clay-containing polypropylene nanocomposites. in 'Processing of polymer-based nanocomposites' (ed.: Sinha Ray S.) Springer, Basel, Vol 277, 127-154 (2018).

https://doi.org/10.1007/978-3-319-97779-9 5

[9] Badji A. M., Ly E. H. B., Ndiaye D., Diallo A. K., Kebe N., Verney V.: The effect of poly-ethylene-co-glycidyl methacrylate efficiency and clay platelets on thermal and rheological properties of wood polyethylene composites. Advances in Chemical Engineering and Science, 6, 436-455 (2016).

https://doi.org/10.4236/aces.2016.64040

[10] Hong C. K., Kim M-J., Oh S. H., Lee Y-S., Nah C.: Effects of polypropylene- $g$-(maleic anhydride/styrene) compatibilizer on mechanical and rheological properties of polypropylene/clay nanocomposites. Journal of Industrial and Engineering Chemistry, 14, 236-242 (2008).

https://doi.org/10.1016/j.jiec.2007.11.001 
[11] Abdel-Goad M.: Rheological characterization of melt compounded polypropylene/clay nanocomposites. Composites Part B: Engineering, 42, 1044-1047 (2011). https://doi.org/10.1016/j.compositesb.2011.03.025

[12] Durmus A., Kasgoz A., Macosko C. W.: Linear low density polyethylene (LLDPE)/clay nanocomposites. Part I: Structural characterization and quantifying clay dispersion by melt rheology. Polymer, 48, 4492-4502 (2007).

https://doi.org/10.1016/j.polymer.2007.05.074

[13] Xie S., Harkin-Jones E., Shen Y., Hornsby P., McAfee M., McNally T., Patel R., Benkreira H., Coates P.: Quantitative characterization of clay dispersion in polypropylene-clay nanocomposites by combined transmission electron microscopy and optical microscopy. Materials Letters, 64, 185-188 (2010).

https://doi.org/10.1016/j.matlet.2009.10.042

[14] Abbasi F., Tavakoli A., Aghjeh M. K. R.: Rheology, morphology, and mechanical properties of reactive compatibilized polypropylene/polystyrene blends via Friedel-Crafts alkylation reaction in the presence of clay. Journal of Vinyl and Additive Technology, 24, 18 26 (2018).

https://doi.org/10.1002/vnl.21522

[15] Zdiri K., Elamri A., Hamdaoui M.: Advances in thermal and mechanical behaviors of $\mathrm{PP} /$ clay nanocomposites. Polymer-Plastics Technology and Engineering, 56, 824-840 (2017).

https://doi.org/10.1080/03602559.2016.1233282

[16] Rueda M. M., Auscher M-C., Fulchiron R., Périé T., Martin G., Sonntag P., Cassagnau P.: Rheology and applications of highly filled polymers: A review of current understanding. Progress in Polymer Science, 66, 22-53 (2017).

https://doi.org/10.1016/j.progpolymsci.2016.12.007

[17] Limpanart S., Khunthon S., Taepaiboon P., Supaphol P., Srikhirin T., Udomkichdecha W., Boontongkong Y.: Effect of the surfactant coverage on the preparation of polystyrene-clay nanocomposites prepared by melt intercalation. Materials Letters, 59, 2292-2295 (2005). https://doi.org/10.1016/j.matlet.2005.03.006

[18] ASTM D638-14: Standard test method for tensile propertyies of plastics (2014).

[19] Ghaemi N., Madaeni S. S., Alizadeh A., Rajabi H., Daraei P.: Preparation, characterization and performance of polyethersulfone/organically modified montmorillonite nanocomposite membranes in removal of pesticides. Journal of Membrane Science, 382, 135-147 (2011).

https://doi.org/10.1016/j.memsci.2011.08.004
[20] Alexandre M., Dubois P.: Polymer-layered silicate nanocomposites: Preparation, properties and uses of a new class of materials. Materials Science and Engineering R: Reports, 28, 1-63 (2000). https://doi.org/10.1016/S0927-796X(00)00012-7

[21] Colombe G., Gree S., Lhost O., Dupire M., Rosenthal M., Ivanov D. A.: Correlation between mechanical properties and orientation of the crystalline and mesomorphic phases in isotactic polypropylene fibers. Polymer, 52, 5630-5643 (2011). https://doi.org/10.1016/j.polymer.2011.09.035

[22] Osswald T. A., Menges G.: Materials science of polymers for engineers. Hanser, Munich (2003).

[23] Lamberti G.: Isotactic polypropylene crystallization: Analysis and modeling. European Polymer Journal, 47, 1097-1112 (2011). https://doi.org/10.1016/j.eurpolymj.2011.02.005

[24] Osswald T. A., Rudolph N.: Polymer rheology fundamental and applications. Hanser Publishers, Munich (2015)

[25] Venkataraman N., Rangarajan S., Matthewson M. J., Harper B., Safari A., Danforth S. C., Wu G., Langrana N., Guceri S., Yardimci A.: Feedstock material property - Process relationships in fused deposition of ceramics (FDC). Rapid Prototyping Journal, 6, 244-252 (2000). https://doi.org/10.1108/13552540010373344

[26] Chen R-Y., Zou W., Zhang H-C., Zhang G-Z., Yang Z-T., Jin G., Qu J-P.: Thermal behavior, dynamic mechanical properties and rheological properties of poly(butylene succinate) composites filled with nanometer calcium carbonate. Polymer Testing, 42, 160-167 (2015). https://doi.org/10.1016/j.polymertesting.2015.01.015

[27] Pfeifer T., Koch C., van Hulle L., Mazzei G. A., Rudolph N.: Optimization of the FDM additive manufacturing process. in 'Proceedings of ANTEC. Indianapolis, USA', 22-29 (2016).

[28] Aumnate C., Pongwisuthiruchte A., Pattananuwat P., Potiyaraj P.: Fabrication of ABS/graphene oxide composite filament for fused filament fabrication (FFF) 3D printing. Advances in Materials Science and Engineering, 2018, 2830437/1-2830437/9 (2018).

https://doi.org/10.1155/2018/2830437 